\title{
Dificuldades de atenção e hiperatividade na perspectiva histórico-cultural
}

\author{
Solange Aparecida da Rosa
}

\begin{abstract}
Resumo
Texto elaborado, principalmente, a partir dos resultados de uma pesquisa-intervenção que teve como objetivos identificar relações entre o desenvolvimento da vontade na criança e as dificuldades características relacionadas ao Transtorno de Déficit de Atenção e Hiperatividade (TDAH), e contribuir para a elaboração de intervenções alternativas ao uso de medicação. Frente à polarização nas discussões, ora em aspectos individuais, naturalizando-se o social, ora em aspectos sociais, desconsiderando-se a dimensão individual, buscou-se superar a dicotomia entre indivíduo e sociedade na compreensão do suposto TDAH. Constatou-se que é possível modificar o funcionamento psicológico - as relações diretas entre percepção-motricidade e pensamento-fala - e superar dificuldades de atenção por meio do desenvolvimento do pensamento reflexivo e das capacidades de planejamento, controle e avaliação. Entende-se que as intervenções devem ter, como foco, não somente o indivíduo, mas também as relações interpsicológicas da criança, suas atividades e o meio histórico-cultural no qual ela está inserida.
\end{abstract}

Palavras-chave: Transtorno de déficit de atenção e hiperatividade, educação, psicologia.

\section{Attention difficulties and hyperactivity in historical-cultural perspective}

\begin{abstract}
The text was developed, mainly, from the results of research-intervention, that has had as its goal to identify relations between the development of the will in children and the characteristic difficulties related to Attention Deficit Disorder and Hyperactivity (TDAH), and to contribute with the develop of alternative interventions to the use of medication. Facing the polarization in discussions, sometimes in individual aspects, becoming natural the social, sometimes in social aspects, without taking in to account the individual dimension, it was aimed to overcome the dichotomy between individual and society in the comprehension of the supposed TDAH. It is possible to modify the psychological functioning - the direct relations between perception-motricity and thought-speaking -, and to overcome the difficulties of attention through the development of reflexive thought and planning, control and evaluation capacities. It is understood that the interventions must have as focus, not only the individual, but also the inter-psychological relations of the child, the activities, the historical-social environment where the child is inserted.
\end{abstract}

Keywords: Attention deficit disorder and hyperactivity, education, psychology.

\section{Dificultades de atención e hiperactividad en la perspectiva histórico-cultural}

\section{Resumen}

Texto elaborado, principalmente, a partir de resultados de una investigación-intervención que tuvo como objetivos: identificar relaciones entre el desarrollo de la voluntad en el niño y las dificultades características relacionadas al Trastorno de Déficit de Atención e Hiperactividad (TDAH); y, contribuir para la elaboración de intervenciones alternativas al uso de medicación. Frente a la polarización en las discusiones, a veces en aspectos individuales, naturalizándose lo social, a veces en aspectos sociales, desconsiderándose la dimensión individual, se buscó superar la dicotomía entre individuo y sociedad en la comprensión del supuesto TDAH. Se constató que es posible modificar el funcionamiento psicológico - las relaciones directas entre percepción-motricidad y pensamiento-habla - y superar dificultades de atención por medio del desarrollo del pensamiento reflexivo y de las capacidades de planificación, control y evaluación. Se entiende que las intervenciones deben tener, como foco, no solamente al individuo, sino también las relaciones inter-psicológicas del niño, sus actividades y el medio histórico-cultural en el que se encuentra. Palabras Clave: Trastorno por déficit de atención con hiperactividad, educación, psicología. 


\section{Introdução}

As concepções biologizantes ou naturalizantes da constituição do psiquismo humano vêm se fortalecendo como explicações para as dificuldades cognitivas e de aprendizagem das crianças. Um movimento, segundo Souza (2010), de "retorno à patologia para justificar a não aprendizagem escolar", resultando na "medicalização do processo de ensino-aprendizagem" (Collares \& Moysés, 2010). No campo da Psicologia Escolar e Educacional, de acordo com Souza (2010), vem se tentando realizar, desde a década de 1980, uma ruptura com as concepções organicistas e com as práticas adaptacionistas e medicalizantes do processo de escolarização e dos problemas de aprendizagem. Contudo, o retorno das referidas concepções indica que tal ruptura ainda não foi definitiva, impondo-se a necessidade de se aprofundar a reflexão e o debate teórico sobre as teorias do desenvolvimento humano e sobre as práticas estabelecidas que envolvam crianças e os processos de escolarização.

Diante do aumento considerável de diagnósticos de TDAH $^{1}$ e do "dramático aumento do uso de metilfenidato", indicados por Collares e Moysés (2010), entende-se ser importante analisar as dificuldades de atenção e de aprendizagem de crianças em processo de escolarização a partir de outras perspectivas teóricas e em contraposição às teorias e práticas indicadas, o que se objetiva fazer neste texto. Tal discussão será realizada a partir dos resultados de uma pesquisa-intervenção realizada junto a duas crianças de oito anos de idade, envolvendo suas famílias e a escola pública de Ensino Fundamental em que as duas crianças estudavam. Destaque-se que uma das crianças tinha diagnóstico médico de Transtorno de Déficit de Atenção e Hiperatividade (TDAH) e a outra estava em processo de avaliação por apresentar dificuldades de atenção em sala de aula.

A referida pesquisa, finalizada em 2003 , teve como objetivos identificar relações entre o desenvolvimento da vontade na criança e as dificuldades características relacionadas ao TDAH, e contribuir para a elaboração de alternativas ao uso de medicação nos casos em que, entende-se, façam-se necessárias intervenções visando aos interesses de todos os sujeitos envolvidos, mas principalmente da própria criança. Discussão que remete a questões de cunho teórico, político e econômico, pois pensar intervenções demanda refletir sobre as políticas públicas vigentes.

Ao mesmo tempo, tais discussões impõem a necessidade de se refletir sobre a formação escolar possibilitada nas escolas públicas brasileiras neste final de século $X X$ e início do século XXI, assim como as relações entre a Educação e a Psicologia, visto ser a Psicologia uma das ciências envolvidas no diagnóstico e tratamento do suposto transtorno. Para a realização das análises, procurou-se ter como

1 De acordo com a Associação Brasileira do Déficit de Atenção (ABDA), o Transtorno do Déficit de Atenção com Hiperatividade (TDAH) é um transtorno neurobiológico, de causas genéticas, que aparece na infância e frequentemente acompanha o indivíduo por toda a sua vida, caracterizando-se por sintomas de desatenção, inquietude e impulsividade. Disponível em http://www.tdah.org.br, acesso em 07/05/2011. referência os aportes do materialismo histórico dialético e as contribuições da Psicologia Histórico-cultural e da Pedagogia Histórico-crítica.

Este texto inicia com algumas discussões sobre as relações entre a Educação e a Psicologia, visando a uma reflexão sobre como a Psicologia vem se colocando no debate referente às temáticas indicadas. Num segundo momento, apresentar-se-á, de forma sucinta, a concepção sobre o desenvolvimento humano que fundamenta as discussões realizadas. Posteriormente, serão apresentados dois estudos de caso, para então finalizar o texto com uma síntese das principais considerações e entendimentos que os estudos permitiram elaborar.

\section{A Psicologia e a Educação entre o "psicologismo" e o "sociologismo"}

A Psicologia vem sendo criticada desde a década de 1980 por suas concepções organicistas, naturalizantes e individualizantes e por suas práticas adaptacionistas. De acordo com Bock (2000), a ideia da existência de uma "natureza humana" é uma das ideias mais camufladoras que se produziu no conjunto das teorias e concepções psicológicas. Para a autora,

Pensar o homem a partir da natureza humana é encobrir toda história social da constituição do humano. É pensar o homem como naturalmente humano. Ocultar a determinação social do homem e deslocá-lo da realidade social que o constitui e lhe dá sentido é um trabalho ideológico que a Psicologia precisa superar, pois esse trabalho de ocultamento permite que a Psicologia se alinhe às construções ideológicas mais perversas em nossa sociedade, tornando aquilo que é social e histórico em algo natural e universal, no qual não se pode mexer e não se pode mudar. (Bock, 2000, p. 14).

Diante destas concepções individualizantes e naturalizantes, do "psicologismo" em Educação e das críticas a estas concepções e práticas promovidas também por abordagens críticas em Psicologia Escolar e Educacional, há uma tendência no campo da Educação em se desvalorizar contribuições da Psicologia, o que pode ser tão prejudicial à Educação quanto o próprio psicologismo. De acordo com Rosa e Serrão (2009),

[...] se algumas abordagens psicológicas produzem conhecimentos alinhados com a ideologia dominante e reduzem a complexidade dos fenômenos psicológicos aos aspectos intrapsíquicos, os conhecimentos produzidos por determinadas apropriações de parcela das contribuições do campo da Sociologia da Educação se polarizam num outro extremo: tendem a se caracterizar pela denúncia do aspecto reprodutor da escola, sem considerar as importantes e necessárias contribuições da educação escolar para a formação dos seres humanos [...] (Rosa \& Serrão, 2009, p. 10). 
As denúncias do aspecto reprodutor e disciplinador da escola, desconsiderando-se as possíveis e necessárias contribuições da educação escolar para o desenvolvimento humano, são prejudiciais aos sujeitos que estão em processo de formação de suas "funções psicológicas superiores", de sua "livre individualidade", por contribuírem, mesmo que não intencionalmente, para a fragilização da escola na sua luta por melhores condições e qualidade de ensino. Tendência que se está denominando de "sociologismo" em Educação e Psicologia, pois ainda que as críticas ao "psicologismo" em Educação tenham se originado dentro do próprio campo psicológico, como afirma Souza (2010), tais críticas foram formuladas a partir de importantes contribuições da Sociologia.

Não se questionam a necessidade e a importância em se analisar a educação escolar e as práticas pedagógicas a partir de concepções críticas, dentre estas as sociológicas. Entretanto, ao se explicar o "todo" pela análise de uma parte, ou se polarizar as discussões em aspectos sociais, políticos e econômicos, menosprezando-se o indivíduo ou os aspectos individuais envolvidos, além de se negligenciar aspectos importantes relacionados ao desenvolvimento humano ou à formação da individualidade, desconsidera-se a relação indivíduo-sociedade. Enfoca-se o polo social desta relação, perdendo-se a possibilidade de análises que expliquem suficientemente os fenômenos estudados, incluindo-se neste rol o fenômeno que se tem atualmente denominado "TDAH".

Como consequência do "psicologismo" e do "sociologismo" em Educação e Psicologia e das mais diversas críticas às tradicionais práticas psicológicas, parece haver também, no campo da Psicologia Escolar e Educacional, receios em se intervir junto aos sujeitos e especialmente junto às crianças, temendo-se um possível retorno às concepções individualizantes e naturalizantes da constituição do psiquismo humano e às práticas adaptacionistas e medicalizantes do processo de escolarização e dos problemas de aprendizagem.

O "enfrentamento" desta situação paradoxal da Psicologia Escolar e Educacional exige teorias e práticas críticas e não dicotômicas; contudo, como realizar intervenções nesta perspectiva, se há indicativos de que a formação básica em Psicologia continua pautada, por um lado, em concepções naturalizantes, não históricas do ser humano (criança) e, por outro, em concepções que, ao enfocarem o social e o institucional enfatizam um dos polos da díade "indivíduo-sociedade", menosprezando a dimensão individual?

\section{Elementos de uma teoria histórica e dialética do desenvolvimento humano}

As abordagens críticas em Psicologia que se pautam no materialismo histórico dialético têm buscado superar algumas dicotomias na compreensão dos fenômenos humanos como, por exemplo, as dicotomias entre interno-externo, psicológico-social e/ou indivíduo-sociedade. Nesta abordagem teórica, resgata-se a individualidade sem cair em noções individualistas "que isolam o indivíduo do seu mundo social, mundo este que lhe constitui e lhe dá sentido" (Bock, 2000, p. 27).
Destaque-se que, nesta perspectiva, o termo social não se reduz apenas à existência de outros homens, nem se resolve a relação biológico-social pela junção ou articulação simplista entre as dimensões biológica, psicológica e social, como muitas vezes se verifica nos entendimentos expressos por meio da palavra "biopsicossocial". Entende-se que, ainda que indivíduo e sociedade constituam um par dialético, o social tem prioridade ontológica nesta relação. A constituição da individualidade é um processo de construção em cada novo representante da espécie, em cada novo indivíduo, das conquistas historicamente acumuladas pela humanidade que se objetivam no social, nos objetos, na linguagem, nas práticas e relações sociais.

Nesta perspectiva, entende-se também que o processo de humanização ou de desenvolvimento humano é regido por leis culturais e não biológicas. Como afirma Leontiev (1978), o processo de hominização - como mudanças essenciais na organização física do homem - termina com o surgimento da história social da humanidade. De acordo com o autor, a passagem do homem a uma vida em que sua cultura é cada vez mais elevada não exige mudanças biológicas hereditárias. O autor afirma ainda que formar no homem novas características psicofisiológicas, novas funções psíquicas, por meio do processo de apropriação dos fenômenos externos da cultura material e intelectual, constitui-se em um processo de Educação. Segundo o autor,

[...] é nisto que se diferencia a aprendizagem humana da aprendizagem dos animais. Enquanto nos animais é uma adaptação individual às condições de existência, no homem é um processo de reprodução, nas propriedades do indivíduo, das propriedades e aptidões historicamente formadas na espécie humana. O animal "se contenta" com o desenvolvimento da natureza, o homem constrói sua "natureza". As aptidões e funções que se desenvolvem no decurso da história social da humanidade não se fixam no cérebro do homem e não se transmitem conforme as leis da hereditariedade. [...] O homem individual possui ao nascer uma única aptidão que o distingue de seus antepassados animais: a aptidão para formar aptidões humanas. (Leontiev, 1978, p. 288).

Analisando especificamente o desenvolvimento humano e o processo de desenvolvimento das funções psicológicas culturalmente organizadas, Vigotski (1998, 2000) afirma que aprendizagem adequadamente organizada promove desenvolvimento e que, antes que as Funções Psicológicas Superiores (FPS) ocorram como uma atividade interna (intrapsíquica), estas ocorrem, necessariamente, como atividade externa (interpsíquica). Nisto, segundo o autor, constitui-se a Lei Geral de desenvolvimento das FPS.

De acordo com este autor, as interações entre a criança e as pessoas de seu meio sociocultural permitem o desenvolvimento na criança da fala interior e do pensamento reflexivo, assim como do seu comportamento voluntário. A criança aprende a subordinar o seu pensamento e comportamento às regras sociais. E, uma vez internalizados, tais 
processos se tornam parte das aquisições do desenvolvimento real da criança. A partir destas concepções, iniciamos um processo de estudo sobre o desenvolvimento humano, mais especificamente da atenção humana, objetivando compreender como se configuram no indivíduo suas dificuldades de atenção.

\section{O desenvolvimento da atenção como manifestação da vontade}

Para Vigotski (1998), a dimensão cognitiva ou intelectual, a dimensão emotiva e a motivacional são partes de um mesmo todo dialético denominado psiquismo, o qual funciona como um conjunto de sistemas psicológicos. De acordo com o autor, o desenvolvimento das funções psicológicas superiores é fundamental para a orientação e a tomada de decisão pelo homem ante a realidade externa e diante de si mesmo. Habilidades de orientação e avaliação que se manifestam em formas complexas como a reflexão, a regulação da conduta e das atividades, a elaboração pessoal de opiniões e a tomada de decisões, entre outras. Estas habilidades, segundo Vigotski (1998), dependem, também, do desenvolvimento volitivo do ser humano.

Estando a atenção voluntária intrinsecamente relacionada às esferas cognitiva e emotiva, não se pode entendê-la de forma separada desse processo, nem o seu desenvolvimento em separado dos processos de aprendizagem. Em relação a este aspecto, Labarrere-Sarduy (1995) destaca que, para que o sujeito tome consciência e compreenda a importância de se exercer controle sobre sua própria atividade cognitiva, ou seja, para que exerça uma atividade consciente, é necessário o desenvolvimento de sua autonomia.

O autor, fundamentando-se na Teoria da Atividade de Leontiev, aponta alguns aspectos a serem considerados em um processo de direção da atividade da criança que vise à formação e ao desenvolvimento de suas habilidades e de sua autonomia: claridade dos objetivos que se desejam alcançar, assim como dos caminhos possíveis a serem seguidos; consciência da necessidade e importância dos objetivos; e disposição do sujeito. É importante salientar que o controle do andamento do processo, assim como as correções necessárias, pode e deve ser realizado, pela criança, com ajuda externa, isto é, inicialmente a criança precisa de ajuda para controlar seus comportamentos e atividades cognitivas.

É no processo de realização de suas atividades - e principalmente na realização das atividades de aprendizagem escolar - que a criança, ao aprender com ajuda externa a se organizar, controlar-se e a operar cognitivamente, vai apropriando-se dos modos de organização, controle e pensamentos adotados socialmente para torná-los seus e conseguir se gerir e se organizar de forma autônoma. Processo que, inicialmente, ocorre de forma não crítica, não reflexiva, mas, no decorrer do desenvolvimento da consciência - de uma consciência em-si a uma consciência para-si -, o sujeito passa a gerir-se e a organizar-se de forma não só autônoma, mas também crítica e reflexiva, adquirindo, segundo
Labarrere-Sarduy (1995), sua "emancipação cognitiva, intelectual, social e cultural".

Na perspectiva da Teoria da Atividade, entende-se que o desenvolvimento da capacidade de volição ou autonomia cognitiva e intelectual está diretamente relacionada às necessidades do sujeito e ao desenvolvimento de suas habilidades prospectivas (de planejamento), de controle e execução de sua própria conduta, de sua própria atividade. E, de acordo com Vigotski (1998), a volição, ou seja, a singular liberdade intencional que o homem possui de criar intenções é mais desenvolvida nos adultos do que nas crianças, o que evidencia seu caráter sócio-histórico. O ato volitivo - ou livre-arbítrio -, assim como as demais funções psicológicas, está intrinsecamente relacionado tanto com a linguagem e a apropriação de conceitos quanto com a atividade da criança. O livre-arbítrio, principal traço diferenciador do homem em relação ao animal, é adquirido com o desenvolvimento da autonomia da conduta, o que acontece por meio do desenvolvimento do pensamento.

Como afirma Vigotski (1998), no processo de aquisição da linguagem, a criança dá um salto qualitativo em seu desenvolvimento, libertando-se de seu campo sensorial, pois a palavra e o significado a ela relacionado situam a criança em uma posição radicalmente nova. Para Vigotski, esse processo altera radicalmente o ato da percepção humana e cria a possibilidade do livre-arbítrio, pois, ao mesmo tempo em que se apropria das definições funcionais dos conceitos, a criança aprende a controlar seu próprio comportamento, desenvolvendo sua vontade.

Segundo este autor, o comportamento humano é guiado pelos significados e pelas motivações que incitam as ações, significados e motivações que não estão nitidamente separados da atividade prática, da realidade concreta, nem diretamente ou imediatamente relacionados. A atenção voluntária, segundo este autor, é orientada por significados construídos socialmente, os quais são apropriados pela criança, ou seja, a atenção voluntária está intrinsecamente ligada aos significados e aos valores sociais, e é constituída por eles.

Resumindo, no que concerne à atenção, é possível afirmar que esta, assim como as demais funções psicológicas especificamente humanas, desenvolve-se de forma culturalmente organizada e mediada. A atenção não funciona de forma isolada, mas forma conexões com as demais funções psicológicas superiores, funcionando na forma de sistemas psicológicos. Esta função, num primeiro momento, mantém conexões imediatas com as demais funções psicológicas, especialmente com a percepção, com o sistema psicomotor e com as emoções. Somente paulatinamente, esta função adquire uma notável independência, libertando-se parcialmente de suas conexões imediatas (diretas) com a percepção, com as reações emocionais e com a motricidade, processo em que se configuram novas conexões interfuncionais.

Entende-se que é possível, com a ajuda do poder indicativo das palavras (linguagem), orientar e manter o foco da atenção. Processo que ocorre, num primeiro momento, 
apoiado no poder indicativo das palavras de outras pessoas para depois ocorrer por meio de um diálogo consigo mesmo. Ou seja, este processo ocorre primeiro nas relações interpsicológicas para depois ser internalizado pela criança.

O exposto permite concluir, por dedução lógica, que as dificuldades de atenção também têm origem nas relações interpsicológicas e, ao serem internalizadas, passam a constituir o modo de ser e operar cognitivamente do indivíduo. Apresentar-se-á agora a pesquisa-intervenção realizada, a partir dos fundamentos teóricos indicados, junto a duas crianças, uma com diagnóstico de TDAH e outra em processo de avaliação por apresentar dificuldades de atenção na escola.

\section{Apresentação de casos}

\section{Caso 1}

Menino, de oito anos (idade cronológica), estudante da $3^{a}$ série do Ensino Fundamental, diagnosticado com TDAH, com predominância de hiperatividade, e medicado com Ritalina, apresentando como principais características na escola: agitação; dificuldades em permanecer sentado para realizar as atividades em sala de aula; falar "o tempo todo"; dificuldade de organização; distração com estímulos externos à sua atividade; mexer-se o tempo todo enquanto sentado junto à carteira; dificuldades em esperar a sua vez de falar; entre outros. Isso resultou em reclamações das professoras em relação ao seu comportamento.

Contudo, esta criança não apresentava problemas de aprendizagem; ao contrário, de acordo com suas professoras, era muito inteligente e sempre realizava todas as atividades. Em casa, além das características anteriormente indicadas, o menino agredia frequentemente o irmão menor (três anos), desafiava a autoridade dos pais e colocava-se em situação de perigo (andar de patins, próximo à sacada do apartamento, por exemplo). Em outras palavras, o menino "perturbava" em casa e em sala de aula. A escola e a família reclamavam do comportamento do menino e entendiam ser necessário o uso de medicação para acalmá-lo (um processo de contenção química).

Optou-se por realizar um processo de intervenção junto a esta criança, a sua família e a sua professora, pois o menino solicitava ajuda para poder parar de tomar remédio, afirmando que o remédio lhe provocava "mal estar", "era ruim", e que ele "não gostava" de tomar o remédio; mas também porque se entende que a aprendizagem escolar é importante para o desenvolvimento humano, como indicado anteriormente, e um direito de todas as crianças, inclusive dos colegas deste menino que conviviam com ele em sala de aula e tinham seu processo de aprendizagem dificultado por seu comportamento.

Se a aprendizagem escolar não depende de uma disciplina rígida e autoritária - o que, ao contrário, pode ser prejudicial à aprendizagem e à formação de sujeitos críticos -, por outro lado, entende-se que é necessário um mínimo de organização, assim como esforços para manter a atenção concentrada e para acompanhar o pensamento dos ou- tros - professores e colegas. Ou seja, é necessário ter, por meio da vontade e do livre-arbítrio, domínio sobre si mesmo. Capacidades que não são naturais aos seres humanos e precisam ser formadas em cada novo representante da espécie por meio de processos educativos.

Entende-se que, quando os processos educativos vivenciados pelo sujeito não lhe possibilitaram o desenvolvimento indispensável de suas funções psicológicas, de sua vontade e de sua autonomia, fazem-se necessários processos reeducativos. Contudo, a família e a escola, como não tinham tal entendimento, tratavam o menino como se fosse um doente, portador de uma doença incurável, diante da qual restava apenas realizar contenção química por meio de medicamentos. Logo não Ihe faziam exigências, nem Ihe orientavam em como proceder, como se faz com uma criança entendida como "normal". Frente ao diagnóstico de TDAH, entendiam que nada podiam fazer: "coitadinho, ele é assim mesmo, fazer o quê?".

\section{Caso 2}

Menina, de oito anos (idade cronológica), estudante da $3^{a}$ série do Ensino Fundamental, em processo de avaliação para se confirmar ou não o diagnóstico de TDAH, com predominância de desatenção, e recebendo acompanhamento de profissional psicopedagogo em Centro de Atendimento Psicológico Infantil (CAPSi). A menina apresentava como principais características na escola: dificuldades em finalizar atividades do cotidiano de sala de aula; dificuldades para se organizar e organizar suas tarefas; desatenção - às vezes parecia não ouvir quando a professora falava com ela; entre outros.

Neste caso, a criança apresentava dificuldades de aprendizagem; contudo, as professoras não reclamavam de seu comportamento, pois esta criança não perturbava o "ambiente" de sala de aula. Em casa, além das características anteriormente indicadas, a menina apresentava dificuldades para se organizar em suas atividades cotidianas. Distraía-se com facilidade, era esquecida, perdia coisas necessárias às suas atividades, como lápis, calçados, brinquedos etc. A mãe a orientava e controlava o tempo todo: "calce os chinelos"; "está na hora de fazer os temas"; "segure direito este copo"; "responda ao fulano, ele está falando com você"; "não é assim que se faz, preste atenção"; "cuidado para não derramar"; "preste atenção no que estão falando"; "amarre os cadarços" etc.

A escola e a família percebiam que a criança precisava de ajuda para superar suas dificuldades, mas não percebiam que a mãe, por sua atitude excessivamente diretiva, impedia que a criança aprendesse a organizar-se e a planejar suas atividades com mais autonomia. Atitude diretiva que não se verificava na escola; ao contrário, as professoras, por acreditarem que esta criança era portadora de uma doença incurável - mesmo antes que o diagnóstico tivesse sido confirmado -, não lhe ofereciam a ajuda necessária em sala de aula para que esta pudesse aprender a manter sua atenção e a organizar-se, superando suas dificuldades. 
Optou-se por realizar um processo de intervenção pelo fato de esta criança apresentar dificuldades de aprendizagem e estar sendo prejudicada em seu desenvolvimento, tendo-se como parâmetro as máximas possibilidades postas para o desenvolvimento do gênero humano, especialmente no que refere ao desenvolvimento da atenção voluntária, mas também de todo o sistema de funções psicológicas superiores, pois entende-se, em acordo com Vigotski, que os conteúdos escolares são importantes para o desenvolvimento humano.

\section{Metodologia da pesquisa-intervenção}

Definidas quais as crianças que participariam da pesquisa-intervenção, realizaram-se entrevistas com todos os envolvidos. Num segundo momento, foram feitas observações no contexto escolar e familiar. Posteriormente, após reflexões, elaboraram-se juntamente com os envolvidos crianças, familiares e professoras - os "planos de ação". Buscou-se possibilitar às crianças o desenvolvimento de suas capacidades de reflexão, de planejamento, controle e avaliação, por meio de modificações nos modos como se dava a sua inserção e participação nas atividades cotidianas realizadas junto à família e no processo de ensino-aprendizagem. Entendia-se que a participação nestas atividades deveria dar-se de forma a possibilitar o desenvolvimento da autonomia das crianças. A proposta de intervenção foi elaborada com base no Método elaborado por Vigotski (2000) e na Teoria da Atividade de Leontiev.

Discutiu-se com os pais sobre a necessidade de incluírem seus filhos nos processos decisórios relacionados às suas vidas (atividades), buscando-se, por meio do diálogo, possibilitar o desenvolvimento de suas capacidades de reflexão, planejamento, controle da própria atividade/ comportamento e avaliação. Discussão realizada também com as professoras das duas crianças, tendo em vista que, nas escolas brasileiras, de modo geral, as ações de planejamento, controle e avaliação das atividades são centralizadas pelo professor, restando à criança a execução das mesmas. Processo que dificulta o desenvolvimento nas crianças dessas capacidades, assim como das capacidades de autoavaliação e autocontrole. No caso da menina "desatenta", foi também discutido com as professoras sobre a necessidade de lhe oferecer toda a ajuda externa possível para que ela pudesse se organizar e manter a atenção em sala de aula.

Realizaram-se também alguns encontros e atividades com as crianças em que se discutiram a condição de cada uma, seus motivos diante da aprendizagem escolar - sua relação com o saber na perspectiva indicada por Leontiev (1978) e Charlot (2000) - e seus interesses. Nestes encontros, as crianças também elaboraram um símbolo para ajudá-las a lembrar de seus objetivos e a controlar seus modos de operar cognitivamente - manter a atenção - e de se comportar, o qual deveria funcionar como um instrumento externo, um signo auxiliar.

Tinha-se por objetivo, no caso do menino "hiperativo", desenvolver sua autonomia e que este superasse as relações diretas entre sua percepção-motricidade e pensamento-fala. E, no caso da menina, desenvolver sua autonomia, sua capacidade de organização e de manter, por meio da própria vontade, a atenção diante das atividades.

A maior dificuldade, neste processo, foi conseguir, após todos os sujeitos envolvidos estarem cientes das mudanças necessárias em suas relações e seus modos de ser e operar - e terem concordado com tais mudanças -, que os envolvidos tivessem persistência para superar a tendência à repetição dos modos de ser e operar após estes serem automatizados de uma determinada maneira, como indicado por Leontiev (1978).

\section{Alguns resultados}

Ainda que as famílias e as professoras envolvidas tenham operacionalizado apenas parcialmente os planos de ação elaborados, alguns resultados positivos foram alcançados. Segundo relatos de uma das professoras: "[...] eu percebo assim, que ele [...] para pra pensar um pouco mais. Ele não tem agido muito mais na impulsividade, pelo menos em sala de aula ele não tem sido tão impulsivo como ele era antes [...] e o rendimento dele enquanto aprendizagem é excelente.". A professora apontava que ele ainda era agitado em alguns dias, mas que esta agitação não atrapalhava mais os colegas, nem o andamento das aulas, como anteriormente; afirmando que "agora, quando ele está em sua carteira fazendo algum 'gesto extravagante', ou se mexendo demais, de repente, num sobressalto, ele se dá conta e muda completamente o comportamento, senta-se ereto na carteira e retoma a atividade que estava fazendo, olhando para os lados para ver se alguém percebeu; e, se percebe que eu - a professora - estou olhando, sorri disfarçadamente".

A professora explica que este menino começou a perceber conscientemente seu próprio comportamento e a mudar de atitude por si mesmo, sem que alguém precise chamar sua atenção. Percebeu-se que, no menino, o seu pensamento e sua fala exterior deixaram de ser acompanhados diretamente por ações motoras desnecessárias; da mesma forma, seu pensamento deixou de ser acompanhado diretamente por sua fala exterior.

A família também apontou ter percebido mudanças, afirmando que este estudo tinha os ajudado a se darem conta de que era possível mudar. Um efeito contrário ao das práticas medicalizantes de diagnóstico, as quais resultam no conformismo das famílias e demais sujeitos envolvidos diante da suposta condição patológica existente.

Em relação à menina, constatou-se que seu desempenho escolar melhorou, ela não se atrasava mais para copiar do quadro e conseguia acompanhar a turma. A mãe relatou que a filha já organizava os materiais escolares sem precisar de ajuda e estava fazendo as tarefas escolares por iniciativa própria, avaliando por si mesma o melhor horário para fazê-las.

As professoras apontaram que ela conseguia manter-se mais concentrada em sala e estava muito mais participa- 
tiva nas aulas, em comparação com o ano anterior. Também apontaram que ela estava menos distraída.

Outro aspecto importante que as professoras apontaram é que, anteriormente, quando a menina se distraía, era preciso chamar sua atenção e explicar novamente o que ela deveria fazer, ou seja, explicar a atividade de aprendizagem em andamento na turma, e que agora, nas vezes em que ela se distraía, bastava chamá-la pelo nome e, por si mesma, ela retomava a atividade que estava fazendo: "[...] já sabe o que tem de fazer, está conseguindo se organizar melhor, inclusive no caderno, demonstrando estar mais comprometida com o próprio processo de ensino-aprendizagem". Resumindo, apesar das dificuldades encontradas, mudanças ocorreram, e os sujeitos envolvidos passaram a acreditar na possibilidade de superar as dificuldades anteriormente entendidas como naturais e definitivas.

\section{Considerações finais}

Não se pretendeu, neste texto, entrar na discussão sobre se o TDAH é uma doença orgânica, de ordem neurológica, como se afirma hegemonicamente no campo da Medicina e de determinadas abordagens psicológicas, ou se tal fenômeno não passa de uma forma de medicalização da vida de crianças e dos processos educativos, resultando, como entendido por Moysés e Colares (2010), em mais uma "invenção das doenças do não aprender". Também não se pretendeu discutir os critérios diagnósticos de tal transtorno, os quais são social e culturalmente definidos e modificam-se no decorrer da história, ainda que se saiba da importância do enfrentamento teórico-político necessário diante do uso abusivo de medicamentos e das práticas antiéticas que sustentam uma rede de consumo medicamentoso que resulta em lucros para a indústria farmacêutica, como denunciado por Collares e Moysés (2010).

Partiu-se do entendimento de que o fenômeno existe independentemente de ser classificado como "normal" ou "patológico", ou seja, algumas crianças apresentam dificuldades de atenção, entre outras características psicomotoras, as quais dificultam seu processo de aprendizagem. Entretanto, entende-se que as dificuldades relacionadas ao suposto TDAH - dificuldades de atenção e características como impulsividade e hiperatividade - configuram-se no processo de constituição do sujeito, o qual ocorre na relação com o meio social e por meio de outras pessoas.

Em outras palavras, entende-se que tais dificuldades não têm origem orgânica, ao contrário, originam-se nas relações interpsicológicas para depois serem internalizadas e constituírem-se nos modos individuais característicos de operar cognitivamente dessas crianças. Consequentemente, entende-se que uma intervenção adequada deve ter como foco não somente a criança em si - o indivíduo -, mas também as relações interpsicológicas da criança, suas atividades, os processos de escolarização e o meio histórico-cultural no qual ela está inserida.
Os resultados da pesquisa realizada indicam que é possível superar as referidas dificuldades e que, para tanto, se faz necessário possibilitar o desenvolvimento do pensamento reflexivo e das capacidades de planejamento, controle e avaliação, o que somente é possível se forem mobilizados os interesses do sujeito. Resumindo, modificando-se a forma como se dão as relações que envolvem a criança e o modo como se realizam as suas atividades, é possível modificar o funcionamento de seus sistemas psicológicos - as relações diretas entre percepção-motricidade e pensamento-fala - e superar dificuldades de atenção, tendo em vista as necessidades de cada criança.

Sabe-se que o uso de medicamentos não possibilita as modificações necessárias no funcionamento psicológico - cognitivo, psicomotor e comportamental - de crianças com dificuldades, logo, poderia ser empreendido apenas como um adjuvante no processo de intervenção. Contudo, ante as inúmeras reações adversas do metilfenidato, como denunciado por Collares e Moysés (2010), entre outros pesquisadores, entende-se que tal prática seja desnecessária.

Por saber-se da importância da apropriação dos conteúdos historicamente ensinados nas escolas para o desenvolvimento humano, entendido como um processo histórico, social e cultural, entende-se que todos os esforços devem ser empreendidos para que todas as crianças possam aprender de fato e superar suas dificuldades, tendo em vista as máximas possibilidades de desenvolvimento do gênero humano. Nesta perspectiva, entende-se que investir em educação escolar de qualidade, na ampliação da equipe pedagógica escolar e em intervenções pedagógicas e psicológicas poderia ser mais eficaz e mais econômico para o Estado do que as atuais políticas de atenção pautadas no encaminhamento aos especialistas para realização de avaliação e diagnóstico e no uso de medicamentos como a principal, senão a única, forma de intervenção.

Analisando-se sumariamente esta pesquisa-intervenção, pode-se concebê-la como uma prática adaptacionista; contudo, se analisado com maior profundidade, é possível chegar-se a outras conclusões. Entende-se que o processo de reprodução em cada novo representante da espécie dos modos socialmente estabelecidos de perceber, sentir, pensar, operar cognitivamente, comportar-se e agir é um momento necessário de um processo maior e mais complexo, o processo de emancipação humana. Se o processo de humanização ocorre, num primeiro momento, de forma não crítica, não reflexiva, este é, ainda assim, condição para o desenvolvimento da própria consciência, por meio da qual o sujeito poderá, posteriormente, perceber, sentir, pensar, comportar-se e agir de forma não só autônoma, mas também crítica e reflexiva. Logo, concebe-se que tal prática contribui, de forma mediada, para o processo de emancipação intelectual, cognitiva, social e cultural dos sujeitos. 


\section{Referências}

Bock, A. M. B. (2000). As influências do Barão de Münchhausen na Psicologia da Educação. Em E. R. Tanamachi, M. Proença \& M. L. Rocha (Orgs.), Psicologia e Educação: desafios teórico-práticos (pp. 11-33). São Paulo: Casa do Psicólogo.

Charlot, B. (2000). Da relação com o saber: elementos para uma teoria. Porto Alegre: Artmed.

Collares, C. A. L., \& Moysés, M. A. A. (2010). Dislexia e TDAH : uma análise a partir da ciência médica. Em Conselho Regional de Psicologia de São Paulo \& Grupo Interinstitucional de Queixa Escolar (Orgs.), Medicalização de crianças e adolescentes: conflitos silenciados pela redução de questões sociais a doença de indivíduos. São Paulo: Casa do Psicólogo.

Labarrere-Sarduy, A. F. (1995). La generalización de procedimientos de solución de problemas y la autorregulación de la actividad cognoscitiva de los estudiantes. Em Colección de Autores, El adolescente cubano: una aproximación al estudio de su personalidad. Ciudad de La Habana: Pueblo y Educación.

Leontiev, A. (1978). O desenvolvimento do psiquismo. São Paulo: Moraes.
Rosa, S. A., \& Serrão, M. I. B. (2009). Escola e formação escolar: reflexões a partir da produção do Grupo de Trabalho Educação Fundamental da ANPEd (2000-2005). Anais da 32a Reunião Anual da Associação Nacional de Pós-Graduação em Educação (ANPEd). Caxambú, MG: ANPed. Recuperado: 01 dez. 2010. Disponível: http://www.anped.org.br/reuniões/32ra/arquivos/ trabalhos/GT13-5297--Int.pdf>.

Souza, M. P. R. (2010). Retornando à patologia para justificar a não aprendizagem escolar: a medicalização e o diagnóstico de transtornos de aprendizagem em tempos de neoliberalismo. Em Conselho Regional de Psicologia de São Paulo \& Grupo Interinstitucional de Queixa Escolar (Orgs.), Medicalização de crianças e adolescentes: conflitos silenciados pela redução de questões sociais a doença de indivíduos. São Paulo: Casa do Psicólogo.

Vigotski, L. S. (1998). O desenvolvimento psicológico na infância. São Paulo: Martins Fontes.

Vigotski, L. S. (2000). Obras Escogidas (vol. III., $2^{\text {a }}$ edição). Madrid: Visor.

\section{Sobre a autora}

Solange Aparecida da Rosa (solangerosa@unochapeco.edu.br) Universidade Comunitária da Região de Chapecó - UNOCHAPECÓ.

\section{Endereço de corespondência}

Moacir Moro, n. 0012 E

Bairro Efapi - Ltm. Zanrrosso - Chapecó - SC

CEP: 89809-725

Trabalho elaborado a partir de reflexões sobre os resultados de pesquisa-intervenção realizada na modalidade de TCC, em 2003 , intitulada "Autorregulação e desenvolvimento humano", na qual se deu continuidade a uma pesquisa de iniciação científica realizada em 2002, intitulada "Aprendizagem, dificuldades de atenção e hiperatividade", financiada por verbas destinadas à pesquisa por meio do Artigo 170 da Constituição do Estado de Santa Catarina - realizada com a colaboração de Caroline Franceschetto, também acadêmica do Curso de Psicologia da UNOCHAPECÒ, e sob a orientação da Profa. Christina Pinto da Silva Bastos.

Apresentado anteriormente, na forma de painel, no I Simpósio Internacional "A Educação Medicalizada: Dislexia, TDAH e outros transtornos", realizado na cidade de São Paulo em novembro de 2010. 